\title{
Article
}

\section{The distribution of quantifiers in clefts}

\author{
Kanikli, A
}

Available at http://clok.uclan.ac.uk/13635/

Kanikli, A (2015) The distribution of quantifiers in clefts. Lingua . ISSN 00243841

It is advisable to refer to the publisher's version if you intend to cite from the work.

http://dx.doi.org/10.1016/j.lingua.2015.11.004

For more information about UCLan's research in this area go to

http://www.uclan.ac.uk/researchgroups/ and search for <name of research Group>.

For information about Research generally at UCLan please go to http://www.uclan.ac.uk/research/

All outputs in CLoK are protected by Intellectual Property Rights law, including Copyright law. Copyright, IPR and Moral Rights for the works on this site are retained by the individual authors and/or other copyright owners. Terms and conditions for use of this material are defined in the policies page.

\section{CLoK}

Central Lancashire online Knowledge www.clok.uclan.ac.uk

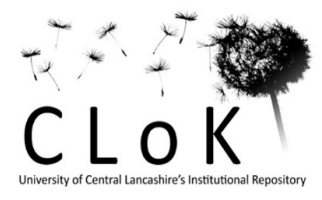




\section{The distribution of quantifiers in clefts}

\section{Abstract}

This paper examines the distribution of quantifiers in clefts. It addresses the fact that quantifiers are not always banned as clefted constituents and discusses analyses which have been proposed in the literature in order to account for this phenomenon. The paper argues that quantifiers qualify for clefted constituents only when they bear a strong reading (Agouraki 2010). Using Cypriot Greek data, it argues that clefts express identificational focus and shows that under this analysis, the distribution of quantifiers, which are sometimes allowed to occur in clefts and sometimes not, can be explained. Quantifiers which have a strong interpretation can express exhaustive identification, whereas quantifiers which bear a weak reading cannot, as they do not satisfy the existence presupposition induced by the cleft clause. The analysis can carry over to crosslinguistic data displaying similar constraints on the distribution of quantifiers in constructions which express identificational focus.

Keywords: clefts; strong quantifiers; weak quantifiers; identificational focus

\section{Introduction}

A prevalent approach to the distribution of quantifiers in clefts is that these are banned as clefted constituents due to the semantic interpretation they bear which is incompatible with the reading clefted constituents may bear, that is identificational focus (É. Kiss 1998). On the basis of this assumption, it has been proposed that in languages in which quantifiers qualify for clefted constituents, clefts express a different meaning than the one expressed in languages like English (cf. Brunetti 2004, Fotiou 2009). In particular, it has been proposed that in these languages clefts do not bear an identificational focus interpretation. This paper argues that the distribution of quantifiers in these structures can in fact be accounted for under an 
identificational focus analysis of clefts ${ }^{1}$. Using Cypriot Greek data, the paper argues that quantifiers may qualify for clefted constituents or not, depending on the reading they bear. Only quantifiers bearing a strong reading are legitimate as clefted constituents (cf. Agouraki 2010). The paper provides an account for this, showing that quantifiers which have a strong interpretation can express exhaustive identification (É. Kiss 1998) over a set of alternatives, whereas weak quantifiers cannot. Under this analysis, the distribution of quantifiers, which are sometimes banned and sometimes allowed to occur in cleft pivots, can be explained.

\section{Previous analyses of the distribution of quantifiers in clefts}

\section{1. É. Kiss's (1998) analysis of the distributional restrictions in Hungarian preverbal foci and English clefts}

É. Kiss (1998:251-253) argues that Hungarian preverbal focalizing constructions and their English equivalent, clefts, display restrictions in the distribution of universal and existential quantifiers. Consider the examples in (1)-(2) which are quoted from É. Kiss (1998:252).

(1) *Mari minden kalapot nézett ki magának.

Mary every hat.ACC picked out herself.DAT

*'It was every hat that Mary picked for herself.'

(2) *Mari valamit nézett ki magának.

Mary something.ACC picked out herself.DAT

*'It was something that Mary picked for herself.'

\footnotetext{
1 Note that identificational focus is not the only type of focus that cleft structures are assumed to express cross-linguistically. Nevertheless, as far as the discussed data is concerned, I argue that this should be analysed as expressing identificational focus.
} 
According to É. Kiss (1998), the occurrence of the universal quantifiers minden and every and the existential quantifiers valamit and something as clefted constituents induces ungrammaticality in (1) and (2) respectively. On the basis of this data, É. Kiss (1998) argues that universal quantifiers and some-phrases are banned in clefts and Hungarian preverbal foci constructions. According to her, universal quantifiers and some-phrases are inherently incompatible with expressing exclusion; that is why they cannot occur in clefts. She considers the ban on universal and existential quantifiers in clefts and preverbal foci constructions as evidence that these constructions express identificational focus.

\subsection{Brunetti's (2004) analysis of the distribution of quantifiers in Italian clefts}

Brunetti (2004) claims that Italian clefts allow for universal, existential and negative quantifiers to be clefted. Adopting É. Kiss's (1998) analysis of the distribution of quantifiers in clefts, she considers that this suggests that Italian clefts do not express identificational focus. The idea is that if Italian clefts expressed identificational focus, these quantifiers would be banned as clefted constituents, as it is the case in English clefts and Hungarian preverbal foci (cf. É. Kiss 1998).

It must be noted that Beninca et al. (1988) argue that quantifiers are not legitimate as clefted constituents in Italian (cf. the examples in (3)), whereas this is not the case with preverbal focalized quantifiers (cf. the examples in (4)). Consider the examples presented by Beninca et al. (1988) (quoted from Brunetti 2004:74-75).

(3) a. *E' qualcuno che sto aspettando.

(it) is someone that (I) am waiting for

b. * E' tutto che è caduto.

(it) is everything that is fallen 
c. 'E' nessuno che (non) ho incontrato.

(it) is nobody that (I) (not) have met

d. ' $\mathrm{E}^{\prime} \quad$ niente che (non) $\mathrm{mi}$ hanno dato da mangiare.

(it) is nothing that (they) (not) to-me-CL have given to eat

(4) a. Qualcuno sto aspettando.

somebody (I) am waiting for

b. Tutto è caduto.

everything is fallen

c. Nessuno ("non) ho incontrato.

nobody (I) (not) have met

d. Niente ("non) mi hanno dato da mangiare.

nothing (they) (not) to-me-CL have given to eat

The above data shows that the existential quantifier qualcuno 'somebody', the universal quantifier tutto 'everything' and the negative quantifiers nessuno 'nobody' and niente 'nothing' may occur in the preverbal stressed position. However, they are banned as clefted constituents. Commenting on the examples in (3) and (4), Brunetti (2004) argues contra Beninca et al. (1988) that existential quantifiers and universal quantifiers are in fact allowed to occur as clefted constituents in Italian, when the appropriate context is given.

(5) a. Stai aspettando l'autobus?

'Are you waiting for the bus?'

b. No, è qualcuno che sto aspettando.

'No, it is someone that I am waiting for.'

\footnotetext{
2 Note that this structure is ungrammatical in Cypriot Greek (cf. also Fotiou 2009).
} 
(6) a. Questa casa ha la cucina molto vecchia.

this house has the kitchen very old

'This house has a very old kitchen.'

b. Non solo la cucina: è tutto qui che crolla a pezzi!

'Not only the kitchen: it's everything here that falls into pieces.'

Brunetti (2004) argues that the existential quantifier qualcuno 'someone' and the universal quantifier tutto 'everything' in (5) and (6), respectively, (quoted from Brunetti 2004:75-76) are legitimate as clefted constituents. According to her, this suggests that Italian clefts do not express exhaustive identification; following É. Kiss (1998), if that was the case universal and existential quantifiers would be banned as clefted constituents in Italian.

Brunetti (2004) further argues contra Beninca et al. (1988) that the negative quantifiers niente 'nothing' and nessuno 'nobody' also qualify for clefted constituents when the negative operator non occurs in the copula clause of the cleft as opposed to the subordinate clause (compare the examples in (7) and (8) (quoted from Brunetti (2004:76)) with the examples in (3c) and 3d)).

(7) a. Sei preoccupata per qualcosa?

'Are you worried about something?'

b. Non, no: non è niente che mi preoccupa. Sono solo molto stanca.

'No, no: it is nothing that I am worried about. I am just very tired.'

(8) a. Qualcuno ti ha detto il mio segreto!

'Somebody told you my secret!' 
b. Non è nessuno che me l' ha detto. L'ho solo intuito.

'It is nobody that told me that. I just guessed it.'3

However, it must be noted that the structures in (7) and (8) sound marginal to many speakers. I will return to this issue in section 6.

The data presented by Brunetti (2004) casts doubt on the idea that quantifiers are banned as clefted constituents. Nevertheless, it does not question the fact that the occurrence of quantifiers as clefted constituents sometimes yields ungrammaticality. It appears that quantifiers are sometimes allowed to occur as clefted constituents and sometimes not. This is something that needs to be accounted for. These questions will be addressed in sections 3 and 5 .

\subsection{Previous analyses of the distribution of quantifiers in Cypriot Greek clefts}

Fotiou (2009) points out that Cypriot Greek and Italian clefts behave similarly with respect to the distribution of quantifiers. In particular, she shows that quantifiers qualify for clefted constituents in Cypriot Greek. Consider some of the examples Fotiou (2009:70) presents.

(9) a. En ULL/ pu enna rtun sto party. is all that will come to the party 'It is everybody that will come to the party.'

b. En I PARAPANO (pu emas) pu apetihan. is the most (of us) that failed 'It is most (of us) that failed.'

\footnotetext{
${ }^{3}$ The anonymous reviewer emphasizes that these structures sound marginal to many speakers.
} 


\section{c. Ennen KANENAS pu ftei. \\ not is nobody that is to be blamed \\ 'It is nobody that is to be blamed.'4}

The quantifiers in (9), namely the universal quantifier ulli all', the group denoting quantifier i parapano 'most' and the Negative Polarity Item kanenas 'nobody', are legitimate as clefted constituents. Following the same line of reasoning with Brunetti (2004), Fotiou (2009) considers that this suggests that Cypriot Greek clefts do not bear an exhaustive identification interpretation. Once again, the idea is that if Cypriot Greek clefts expressed identificational focus, quantifiers could not be clefted.

Commenting on Fotiou's (2009) claim, Agouraki (2010) emphasizes that not every quantifier can be clefted. As Fotiou (2009) herself admits, there are cases where clefting quantifiers yields ungrammaticality. Nevertheless, Fotiou (2009) does not provide an account for this. Discussing this data, Agouraki (2010:549) attempts to identify the quantifiers that cannot be clefted. In particular, she argues that existential quantifiers, stressed or not, distributive universal quantifiers, negative quantifiers, NPIs, counting quantifiers, some EPIs and some group-denoting quantifiers cannot occur as clefted constituents. The universal quantifier ullos 'all', EPIs in the reading 'someone else' and some group-denoting quantifiers (cf. parapano 'most' in (9b)), though, can be clefted. Agouraki (2010) claims that this distinction between the set of quantifiers that qualify for clefted constituents and the set of quantifiers that do not, can be captured in terms of Milsark's distinction

\footnotetext{
${ }^{4}$ Note that this example sounds odd and incomplete to many speakers. Also note that there is a difference between this data and the Italian data in (7) and (8). I will return to these issues in sections 5 and 6.
} 
between strong and weak quantifiers ${ }^{5}$. Nevertheless, the analysis she proposes for Cypriot Greek clefts does not address this. Agouraki (2010) leaves the question as to why only strong quantifiers should qualify for clefted constituents open for further research.

The next section examines the distribution of various types of quantifiers in Cypriot Greek clefts in order to test whether the set of quantifiers that can occur as clefted constituents and the set of quantifiers that cannot, can be captured in terms of the strong-weak distinction.

\section{The distribution of strong and weak quantifiers in Cypriot Greek clefts}

\subsection{Strong quantifiers in cleft pivots}

Consider the following examples in Cypriot Greek which include clefted quantifiers.

(10) En ULLI

(i kalesmeni) pu efian.

is all. MASC.NOM.PL (the guests) that left.3.PL

'It is all (the guests) that left.'

(11) En /

PARAPANO (pu tus kalesmenus) pu efian.

is the.MASC.NOM.PL most

(of the guests)

that left.3.PL

'It is most (of the guests) that left.'

\footnotetext{
5 Note that on the grounds that distributive universal quantifiers (kathe, 'every'), which are considered to bear a strong interpretation (cf. Milsark 1977, de hoop 1992 among many others), are banned as clefted constituents, it is difficult to see how the distribution of quantifiers in clefts can be described in terms of the strong and weak distinction. That is, if strong quantifiers qualify for clefted constituents, we should expect distributive universal quantifiers to be legitimate as clefted constituents. I will return to this issue in section 5 .
} 
(12) En LLII (pu tus kalesmenus) pu efian.

is few.MASC.NOM.PL (of the guests) that left.3.PL

'It is few (of the guests) that left.'

The above examples involve proportional quantifiers in the clefted position. Ulli 'all', $i$ parapano 'the most' and Ilii 'few' express a proportion of the set $i$ kalesmeni 'the guests'; hence, they are called proportional. Proportional quantifiers are taken to be strong quantifiers (cf. Milsark 1977, Barwise and Cooper 1981, de hoop 1992, Kearns 2000 among many others). The grammaticality of the examples in (10)-(12) verifies the expectation that these quantifiers, being strong, qualify for clefted constituents.

\subsection{Weak quantifiers in cleft pivots}

Consider the following examples which involve cardinal quantifiers.

(13a) *En KANENAS fititis pu en efien. ${ }^{6}$

is no.MASC.NOM student that not left.3.SG

(13b) *Ennen KANENAS fititis pu efien. ${ }^{7}$

not is no.MASC.NOM student that left.3.SG

(14) *En ENAS pu efien.

is one.MASC.NOM that left.3.SG

\footnotetext{
${ }^{6}$ Note that the meaning of kanenas 'no' in the examples in (13) is different from the one in (9c). This issue is addressed in section 5 .

${ }^{7}$ Notice that the structure is ungrammatical no matter whether the negative operator en 'not' occurs in the copula clause of the cleft or in the subordinate (cf. Brunetti 2004).
} 

(15) *En $K A P C l$
pu efian. ${ }^{8}$
is some (people).MASC.NOM.PL that left.3.PL

Cardinal quantifiers are considered to be weak quantifiers (cf. Milsark 1977 among many others). The ungrammaticality of the examples in (13)-(15) bears out the expectation that these quantifiers, being weak, should not qualify for clefted constituents.

\subsection{Weak quantifiers with a strong reading in cleft pivots}

Nevertheless, merici 'some', polli 'many' and pente 'five', which are also considered to be weak quantifiers, do not induce ungrammaticality in examples (16)-(18).

(16) En MERICl (fitites) pu efian.

is some.MASC.NOM.PL (students) that left.3.PL 'It is some (of the students) that left.'

(17) En POLLI (fitites) pu efian.

is many.MASC.NOM.PL (students) that left.3.PL 'It is many (of the students) that left.'

(18) En PENTE (fitites) pu efian. is five (students) that left.3.PL 'It is five (of the students) that left.'

\footnotetext{
8 Note that the context, in which the quantifiers in (14)-(15) occur, is one where a set, over which a proportional reading can be acquired, is not given (i.e. Enomiza oti en o Petros pu efie', 'I thought that it is Peter who left'), hence these quantifiers bear a weak reading (cf. the examples in (16)-(19) where such a set (fitites, 'students') is given). I will return to this issue in section 5 .
} 
It appears that the data in (16)-(18) contradicts the idea that weak quantifiers cannot be clefted. However, it must be emphasized that weak quantifiers may bear a strong reading and as such, they may qualify for clefted constituents.

As Milsark (1977) argues, some, the English counterpart of kapci in (15), is ambiguous as to whether it should be interpreted as strong or weak. Kapci 'some' in (15) bears a weak, existential reading, hence it cannot be clefted. It may also bear a strong reading though. Consider the example in (19).
(19) En KAPCl
putus fitites pu efian.
is some.MASC.NOM.PL of the students that left.3.PL
'It is SOME of the students that left.'

Kapci 'some' in partitives bears a strong reading. It denotes 'some subset of appropriate size to be referred as kapci 'some' of the set of students; hence it qualifies as a clefted constituent (Milsark 1977:15). Similarly, merici 'some', polli 'many' and pente 'five' in (16)-(18) express a proportion of the set of students; that is why they may occur in clefts.

The above data shows that the distribution of quantifiers in clefts can in fact be described in terms of the strong-weak distinction. Quantifiers that bear a weak interpretation are banned as clefted constituents, whereas quantifiers with a strong reading can occur in cleft pivots.

The question which arises is why quantifiers qualify for clefted constituents only when they bear a strong reading. I argue that this derives from the interpretation clefted constituents obtain, that is, identificational focus which is incompatible with a weak reading. 
The next section provides evidence that Cypriot Greek clefts express identificational focus and section 5 demonstrates how adopting such an analysis for Cypriot Greek clefts may account for the distribution of quantifiers in cleft pivots.

\section{Cypriot Greek clefts express identificational focus}

Clefts have been analysed as expressing a type of focus which is known as 'contrastive' (Vallduví \& Vilkuna 1998) or 'identificational' focus (É. Kiss 1998)9. As argued in É. Kiss's (1998:245) influential study, in these focalizing constructions the clefted constituent is 'a subset of a set of contextually or situationally given entities' for which the predicate phrase may hold. The clefted constituent is 'identified as the exhaustive subset of this set' for which the predicate phrase holds. É. Kiss (1998) provided evidence that English clefts and Hungarian focalizing structures express identificational focus by applying tests of exhaustive identification to these structures. In what follows, I examine whether Cypriot Greek clefts express this type of focus by applying the tests É. Kiss (1998: 250-1) used, to the Cypriot Greek clefts.

The first test I will apply was designed by Szabolcsi (1981). It consists of two utterances. The first one involves two coordinated DPs in the focus position. The second one involves one of the coordinated DPs in the focus position. If the second utterance is not a logical consequence of the first utterance, it bears exhaustive identification focus. Consider the examples in (20) and (21).

\footnotetext{
9 É. Kiss (1998) argues that contrastive focus is a type of identificational focus. In particular, she claims that in clefts which express exhaustive identification over a closed set of entities that are given in the discourse, the clefted constituents obtain a contrastive focus interpretation. In clefts which express exhaustive identification over an open set of entities that are situationally given, the clefted constituents obtain a -contrastive, +identificational focus interpretation.
} 
(20) a. En ena kappello t je ena palto pu eyorasen i Maria. is one hat.ACC and one coat. ACC that bought.3.SG the Mary.NOM 'It is one hat and one coat that Mary bought.'

b. En ena kappello pu eyorasen i Maria. is one hat.ACC that bought.3.SG the Mary.NOM 'It is one hat that Mary bought.'

(21) a.I Maria eyorasen ena kappello tje ena palto. the Mary.NOM bought.3.SG one hat.ACC and one coat.ACC 'Mary bought one hat and one coat.'

b. I Maria eyorasen ena kappello. the Mary.NOM bought.3.SG one hat.ACC 'Mary bought one hat.'

The utterance in (21b) is a logical consequence of (21a). It does not contradict the meaning expressed by (21a). To this extent, (21b) fails to express exhaustive identification focus. The cleft in (20b), though, is not a logical consequence of (20a). Cypriot Greek clefts, therefore, pass Szabolcsi's (1981) test of exhaustive identification.

The second test of exhaustive identification É. Kiss (1998:251) applied to the Hungarian and English focalizing structures was designed by Donka Farkas (cited in É. Kiss 1998) and consists of a pair of utterances uttered in a context where 'Mary bought a hat'. Compare the examples in (22) and (23).

(22) a. En ena kappello pu eyorasen i Maria. is one hat.ACC that bought.3.SG the Mary.NOM 
'It is one hat that Mary bought.'

b. Oi, eyorasen tfe ena palto.

no bought.3.SG and one coat.ACC

'No, she bought one coat too.'

(23) a. I Maria eyorasen ena kappello.

the Mary.NOM bought.3.SG one hat.ACC

'Mary bought one hat.'

b. \%Oi, eyorasen t te ena palto.

no bought.3.SG and one coat.ACC

'No, she bought one coat too.'

The utterances in (22b) and (23b) express negation of Mary buying only one hat. Therefore, they would be felicitous only as contradicting exhaustive identification. The utterance in (23a) does not express exhaustive identification of the DP ena kappello 'one hat', hence (23b), which expresses negation of exhaustivity, is infelicitous. The cleft in (22a), though, does express exhaustive identification of the clefted constituent ena kappello 'one hat'. That is why $(22 \mathrm{~b})$ is felicitous.

The tests of exhaustive identification provide evidence that Cypriot Greek clefts do express exhaustive identification. A final argument in support of the analysis of Cypriot Greek clefts as expressing exhaustive identification concerns the distribution of even-phrases and also-phrases in Cypriot Greek clefts. Consider the examples in (24) and (25).

(24) *En tfe to kappello pu eyorasen i Maria.

is and the hat.ACC that bought.3.SG the Mary.NOM 
'It is also the hat that Mary bought.'

(25) *En akoma t fe to kappello pu eyorasen i Maria. is even and the hat.ACC that bought.3.SG the Mary.NOM 'It is even the hat that Mary bought.'

Granted that Cypriot Greek clefts express exhaustive identification, the ungrammaticality of the examples in (24) and (25) is straightforwardly explained. The clefts in (24) and (25) identify a subset in the set of entities which Mary bought without excluding other subsets. In other words, the semantics of an even or an alsophrase are incompatible with expressing exhaustivity (É. Kiss 1998:252); hence, they are banned from a clefted position.

Having shown that there is compelling evidence that Cypriot Greek clefts express exhaustive identification focus, let us examine whether under this analysis the distribution of strong and weak quantifiers can be accounted for.

\section{Identificational focus and the strong-weak distinction}

Drawing on previous semantic analyses of exhaustivity in clefts, this section argues that clefts involve two types of presupposition (cf. Reeve 2012, Gribanova 2013): existence presupposition (Jackendoff 1972, Percus 1997, Rooth 1999 among others) and exhaustiveness (Halvorsen 1978, Szabolcsi 1981 among others). Consider the example in (26).

(26) En O PETROS pu espase to vazo.

is the Peter that broke.3.SG the vase

'It is Peter that broke the vase.' 
Existence presupposition entails that there is an $\mathrm{X}$ for which the predicate phrase holds (i.e. someone broke the vase). Exhaustiveness presupposes that the clefted constituent $\mathrm{X}$ (Peter) is the exhaustive $\mathrm{X}$ for which the predicate phrase holds. Notice that exhaustivity presupposes existence (Dekany 2010); that is, a clefted constituent $X$ that does not satisfy the existence presupposition, cannot be identified as the exhaustive $X$ that satisfies the predicate of the cleft clause.

Strong quantifiers are considered to be presuppositional. Many of the analyses proposed for the strong-weak distinction are based on the existence presupposition that strong quantifiers are assumed to carry (Keenan 1987, Diesing 1990, Zucchi 1995, Moltmann 2005 among others). The idea is that strong quantifiers cannot occur in existentials (cf. the "definiteness restriction") because they carry the presupposition that the set of entities over which they quantify is not empty. This is assumed to clash with the semantics of existential structures. On the other hand, quantifiers bearing a weak reading do not bear an existence presupposition, hence they are legitimate in existential structures ${ }^{10}$.

Bearing these in mind, the fact that strong quantifiers may occur in cleft pivots is explained. Strong quantifiers satisfy the existence presupposition of the cleft clause, whereas weak quantifiers fail to do so. Indeed, under this analysis the ungrammaticality in (13) is accounted for.

Kanenas fititis 'no student' in (13) is incompatible with the existence presupposition of the cleft clause as it denotes that the cardinality of the set of entities which are students and left is zero (Reeve 2008). In fact, the distribution of negative quantifiers in focalizing constructions has been used in order to test

\footnotetext{
10 See McNally (forthcoming) for a detailed discussion of the analyses proposed in the literature for the strong-weak distinction.
} 
whether these bear an existence presupposition. Consider the example in (27) quoted from Percus (1997:339).

(27) a. A: Who saw John?

b. B:[Nobody] F saw John.

C. B': *It's [Nobody]F who saw John.

According to Percus (1997), the ban on the presence of nobody as a clefted constituent shows that clefts, unlike focalizing structures such as the one in (27b) (cf. Rooth 1999), carry an existence presupposition. That is, they induce the presupposition that there is an $X$ that has property $\Pi$ which is denoted by the cleft clause. The clefted constituent, which is identified as the exhaustive $X$ that has property $\Pi$, needs to satisfy the existence requirement. Nobody cannot satisfy this requirement, hence the ungrammaticality in (27c). This data suggests that the clefted constituent must satisfy the existence presupposition in order to be compatible with the semantics of the cleft clause. A quantifier that bears a weak reading does not satisfy this requirement; that is why it does not qualify for a clefted constituent.

On the grounds that clefts carry an existence presupposition, the grammaticality of (9c) is unexpected though. Recall that Fotiou (2009) claimed that negative quantifiers may occur in cleft pivots in Cypriot Greek. I argue that kanenas 'no one' in (9c) bears a different meaning than bare negative quantifiers. Adopting a view of exhaustivity in clefts as 'exclusion by identification' (Kenesei 1986, É. Kiss 1998), allows us to account for the grammaticality in (9c).

A structure such as the one in (9c) is uttered in certain contexts. It must be noted that the utterance in (9c) sounds odd and incomplete to many speakers. The oddness of (9c) is cancelled when it is followed by 'en eyo pu fteo', 'It is I that is to be blamed' (see Agouraki 2010:548) as in the example in (28). 

(28) Ennen kanenas
pu ftei,
en $E G O \mathrm{pu}$ fteo.
not is no one that is to be blamed is I that is to be blamed
'It is no one else that is to be blamed, it is me that is to be blamed.'

According to É. Kiss (1998:245), clefts identify the clefted constituent as the exhaustive subset for which the predicate phrase holds excluding a set of contextually or situationally given entities. In the example in (28), evo 'l' is, in fact, the entity that is identified as the exhaustive subset for which the predicate phrase ftei 'is to be blamed' holds, whereas kanenas 'no one else' is the contextually given set of alternatives that is excluded ${ }^{11}$. This data, therefore, does not contradict an analysis of Cypriot Greek clefts as carrying an existence presupposition.

As already argued, on the assumption that clefts induce an existence presupposition which needs to be satisfied by the clefted constituent, the ban on the occurrence of weak quantifiers in cleft pivots can be accounted for. If the analysis is on the right track, we would expect that these quantifiers become legitimate as clefted constituents, when the existence of the set of entities, over which they quantify, is presupposed; that is, when they acquire a strong reading. As pointed out in section 3 (cf. the examples in (16)-(19), this expectation is born out.
(29) a. Akusa
oti merici
fitites efian noris.
heard.1.SG that some.MASC.NOM.PL students left.3.PL early
'I heard that some of the students left early.'

\footnotetext{
11 Note that kanenas (kanenas fititis, 'no student') in (13) bears a different meaning from kanenas 'no one else' in (28). Kanenas fititis 'no student' in (13) is identified as the exhaustive $X$ for which the predicate phrase holds, hence the ungrammaticality of this structure.
} 
b. En POLLI (fitites) pu efian noris. En itan kali idea is many.MASC.NOM.PL (students) that left.3.PL early. not was good idea

na kano party mes tin eksetastiki.

to have party in the exam period

'It is many (of the students) that left early. It was not a good idea to have a party during the exam period.'

Polli 'many' in (29b) denotes that a large proportion of the set of students left. In its vague cardinal, non-proportional reading, polli 'many' denotes a large number, that is, it bears the meaning 'at least $n$ '. The vagueness derives from the 'unspecified choice of $n^{\prime}$ (Partee 1988:241). Note that the meaning of these quantifiers when bearing a strong reading is usually given as a partitive structure (cf. (29b), many of the students). As Diesing (1990) argues, in partitives, the existence presupposition derives from the definite article in the complement of the preposition (cf. of the students). This entails that the set over which the proportion is being measured (the students) is given (Moltmann 2005), hence the proportional reading may obtain (McNally forthcoming:6).

Proportional readings are strong readings, as they presuppose the existence of a set which is part of the background. In the example in (29b), the interlocutors know (roughly) the size of the set of students, hence they are able to judge what counts as a large proportion of this set (Kearns 2000). In a context where the set, over which the proportion can be measured, is not given, the proportional reading of weak quantifiers does not arise. This is the case with kapci 'some' in (15), where the quantifier bears a weak reading (sm people cf. Milsark 1977). Nevertheless, in a context where the background set (the students), over which a proportional reading 
(some of the students) may obtain, is given (cf. the example in (19), kapci 'some' acquires a strong reading and qualifies for a clefted constituent ${ }^{12}$.

(30) a. Akusa oti ulli i fitites efian noris. heard.1.SG that all.MASC.NOM.PL the students left.3.PL early 'I heard that all the students left early.'

b. En KAPCl pu tus fitites pu efian noris. is some. MASC.NOM.PL of the students that left. 3.PL early 'It is some of the students that left early.'

c. En ENAS (fititis) pu efie noris.

is one.MASC.NOM student that left.3.SG early

'It is one of the students that left early.'

On the basis that kapci 'some' and enas 'one' are legitimate as clefted constituents in (30b) and (30c), because the existence of the set $i$ fitites 'the students' is presupposed, we expect that indefinites which express an existential commitment, should also qualify for clefted constituents. The data in $(31)^{13}$ verifies this expectation.

(31) a. Enomiza oti ento Petro pu perimeni i Maria. thought.1.SG that is the Peter.ACC that wait.3.SG the Mary.NOM 'I thought that it is Peter that Mary is waiting for.'

\footnotetext{
12 Notice that a felicitous context for clefting kapci 'some' is one that gives rise to a strong proportional reading.

${ }^{13}$ The examination of structures in which indefinites are legitimate in cleft pivots, was proposed by the anonymous reviewer.
} 
b. Oi, en mia gineka pu perimeni -tin Thomaida loannu, kseris tin? no, is a woman.ACC that wait.3.SG-the.ACC Thomaida loannu,know.2.SG her 'No, it is a woman that she is waiting for -Thomaida loannu, do you know her?'

Mia gineka 'a woman' in (31b) bears a specific reading, that is, it refers to a particular individual, however, unlike a definite NP, it does not entail that the interlocutor is familiar with the individual to which the speaker refers (Kearns 2000). The fact that the interlocutor refers to a particular individual, when uttering (31b), becomes apparent by the fact that the structure sounds better by adding 'Tin Thomaida loannu, kseris tin?', 'Thomaida loannu, do you know her?'. Indefinite NPs which bear specific readings commit to the existence of the entity that they denote (Kearns 2000). This explains why they qualify for clefted constituents. Unlike non-specific indefinites, they satisfy the existence presupposition of the cleft clause.

\subsection{Quantifiers and exhaustive identification}

As argued earlier, clefted constituents should satisfy both types of presuppositions that cleft clauses are assumed to carry. It is evident that strong quantifiers satisfy the requirement that the clefted constituent should carry an existence presupposition. Nevertheless, it is difficult to follow how they may satisfy exhaustivity as defined in É. Kiss (1998). É. Kiss (1998:262) claims that predicative phrases cannot express exhaustive identification as they do not denote individuals and that is why they cannot occur in cleft pivots. A proportional quantifier such as i parapano fitites 'most of the students' does not specify which members of the restriction set the students are members of the proportion that is being expressed. That is, a number of subsets consisting of distinct entities may satisfy this reading. Therefore, a different notion of

exhaustive identification than the one assumed by É. Kiss (1998) needs to be adopted in order to account for the fact that proportional quantifiers (including 
universal quantifiers which according to É. Kiss are banned in cleft pivots) qualify for clefted constituents.

Consider the examples in (32) and (33).

(32) Akusa

oti merici

pu tus kalesmenus efian

noris.

Heard.1.SG that some.MASC.NOM.PL of the guests left.3.PL early

'I heard that some of the guests left early.'

(33) En i PARAPANO pu tus kalesmenus pu efian noris. En itan epitihia to party. is the most of the guests that left3.PL early.Not was success the party 'It is most of the guests that left early. The party was not a success.'

The cleft in (33) identifies i parapano pu tus kalesmenus 'most of the guests' as the exhaustive subset for which the predicate phrase efian 'left' holds, excluding the set of alternatives that is given in the discourse, that is merici pu tus kalesmenus 'some of the guests'. Note that clefting i parapano 'most' does not exclude the complementary subset of the proportion that is being expressed by parapano 'most', but the alternative $\mathrm{X}$ that is given in the discourse: merici pu tus kalesmenus 'some of the guests'.

É. Kiss (1998:252) argued that universal quantifiers cannot express exhaustive identification as they do not exclude a member of the set specified by their restrictor. This assumption entails that clefted elements express exhaustive identification (viewed as 'exclusion by identification') as part of their independent semantic interpretation. If that was the case, it is not clear why they should occur in a cleft structure. In other words, what would be the reading clefted constituents acquire by virtue of their occurrence in a cleft structure, which is different from their independent semantic meaning? The example in (10) shows that universal 
quantifiers are in fact legitimate as clefted constituents. Ulli 'all' in (10) qualifies for a clefted constituent. I argue, contra Fotiou (2009) and Agouraki (2010), that the same holds for the distributive universal quantifier kathe 'every'. Consider the examples in (34)-(35).

(34)

Distihos merici yonis en endiaferunte ja ta pethca tus. unfortunately some.MASC.NOM.PL parents not care.3.PL about the children CL. 'Unfortunately some parents do not care about their children.'

(35) En KATHE yonios pu endiaferete ja ta pethca tu. Aplos i is every parent.NOM.SG that cares about the children CL simply the

alli ennen iperprostateftici opos esi. others not are overprotective like you 'It is EVERY parent that cares about his children. It is just that the other parents are not being overprotective like you.'

Kathe yonios 'every parent' is identified as the exhaustive set for which the predicate phrase in (35) holds, excluding the contextually given alternative merici yonis 'some parents'. Kathe yonios 'every parent' does not exclude any member of its restriction set, but the alternative that is given in the discourse. What is crucial, therefore, is that the quantifier acquires the identificational focus reading because it occurs in the cleft pivot, and 'exclusion by identification' may obtain because an alternative is provided in the discourse.

The above data indicates that strong quantifiers can express exhaustive identification considered as 'exclusion by identification' (Kenesei 1986), but in a way that is different than the one assumed by É. Kiss (1998). Exhaustive identification obtains by excluding the set of alternatives that is given in the context. As shown, it 
is not necessary for clefted constituents to denote individuals. Thus, a notion of exhaustivity that captures the fact that strong quantifiers qualify for clefted constituents needs to be adopted. I argue that clefts identify the constituent in the cleft pivot, which does not necessarily denote individuals, as the exhaustive set for which the predicate phrase holds, excluding the set of alternatives that is contextually given.

In this section, it has been shown that, under an analysis of clefts as expressing exhaustive identification, the distribution of quantifiers in cleft pivots can be explained. Exhaustive identification entails that the clefted constituent satisfies the existence presupposition that is required for exhaustivity to obtain. Quantifiers bearing a weak reading do not satisfy the existence presupposition; that is why they are banned as clefted constituents. Strong quantifiers are presuppositional, hence, they may express exhaustive identification. In light of the discussed data, a notion of exhaustive identification that allows for elements that do not denote individuals to be clefted has been advocated. Exhaustive identification is viewed as 'exclusion by identification', however, not as exclusion of the 'complementary subset' in the sense of É. Kiss (1998:261). What is excluded in clefts is the contextually given set of alternatives. This accounts for the fact that universal quantifiers may, in fact, occur as clefted constituents.

\section{Applying the proposed analysis to crosslinguistic data}

Having shown that Cypriot Greek clefts bear an identificational focus interpretation and that this can account for the distribution of quantifiers in cleft pivots, let us examine whether this can carry over to the Italian data.

Consider again the example in (6) quoted below as (36). 
(36) a. Questa casa ha la cucina molto vecchia.

this house has the kitchen very old

'This house has a very old kitchen.'

b. Non solo la cucina: è tutto qui che crolla a pezzi!

'Not only the kitchen: it's everything here that falls into pieces.'

As already discussed, Brunetti (2004) considers that the fact that tutto 'everything' is acceptable as a clefted constituent in (36) suggests that Italian clefts do not express exhaustive identification. Nevertheless, I argue that the example in (36) does express exhaustive identification. The universal quantifier tutto 'everything' in (36) is identified as the exhaustive set for which the predicate phrase crolla 'falls' holds, excluding the alternative that is given in the discourse, that is, solo la cucina 'only the kitchen'14.

An analysis of the above structure as expressing exhaustive identification is reinforced by the distribution of also-phrases and even-phrases in Italian clefts which is similar to the one in Cypriot Greek clefts (cf. the data discussed in section 4). As Brunetti (2004) points out, anche-phrases and persino-phrases are banned in clefts (see the example in (37) quoted from Brunetti (2004:76)).

(37) *?E' anche/persino il capello che ha comprato Maria.

(it) is also even the hat that has bought Maria

'It was also/even the hat that Maria bought.'

As already argued, also-phrases and even-phrases are incapable of expressing exhaustivity as they cannot express 'exclusion' (É. Kiss 1998:252). The fact that

\footnotetext{
${ }^{14}$ Note that the cleft in (3b) may sound odd to some speakers, not because of the occurrence of tutto (everything) as a clefted constituent, but because it is obscure how identificational focus may obtain given that the context under which $(3 b)$ is uttered is not given.
} 
these phrases cannot occur in cleft pivots provides support for an analysis of these focalizing constructions as expressing identificational focus. Under such an analysis, the fact that tutto 'everything' in (36) qualifies for a clefted constituent can be accounted for. The analysis proposed for the Cypriot Greek data can be applied to the Italian data. In particular, strong quantifiers such as tutto 'everything' may occur in cleft pivots as they satisfy the existence presupposition that is required for exhaustive identification to obtain.

Under this analysis, we would expect negative quantifiers which cannot satisfy the existence presupposition to be banned as clefted constituents. Indeed, the ungrammaticality induced in (3c) and (3d) because of the occurrence of nessuno 'nobody' and niente 'nothing' in the cleft pivot, fulfils this expectation ${ }^{15}$. Nevertheless, Brunetti (2004) argues that there are cases where negative quantifiers may occur as clefted constituents (cf. the examples in (7) and (8) quoted below as (38) and (39).

(38) a. Sei preoccupata per qualcosa?

'Are you worried about something?'

b. Non, no: non è niente che $\mathrm{mi}$ preoccupa. Sono solo molto stanca.

'No, no: it is nothing that I am worried about. I am just very tired.'

(39) a. Qualcuno ti ha detto il mio segreto!

'Somebody told you my secret!'

b. Non è nessuno che me l' ha detto. L'ho solo intuito.

'It is nobody that told me that. I just guessed it.'16

\footnotetext{
15 Note that the ungrammaticality is not cancelled when the negative operator non occurs in the copula clause of the cleft (cf. Brunetti 2004).

${ }^{16}$ As already noted, the anonymous reviewer emphasizes that these structures are marginal for many speakers.
} 
The examples in (38b) and (39b), though, sound marginal to many speakers. The marginality of these structures is cancelled by adding a $c i$, which suggests that these should not be analysed as clefts ${ }^{17}$. Therefore, the analysis proposed for the Cypriot Greek data can, in fact, carry over to the Italian data.

As already discussed, É. Kiss (1998) claims that universal and existential quantifiers are banned as clefted constituents in English clefts and Hungarian preverbal foci (cf. the examples in (1) and (2)). On the grounds that these express identificational focus, we expect that existential quantifiers in their weak reading (cf. section 3) would not be able to occur in cleft pivots. However, we would also expect that strong quantifiers, such as universal quantifiers, would qualify for clefted constituents. As already shown, this is the case for Cypriot Greek and Italian clefts. Dufter (2009) argues that universal quantifiers are in fact legitimate as clefted constituents in English clefts as well. Consider the example in (40) quoted from Dufter (2009:97).

(40) In this case, it is EVERYONE who is being discriminated against.

As argued in section 5, universal quantifiers may occur in cleft pivots provided that an alternative is given in the discourse over which exhaustive identification may obtain. It remains to examine whether, in this context, universal quantifiers may occur in Hungarian preverbal foci as well.

The data discussed in this section suggests that the analysis proposed for the Cypriot Greek data can be applied to focalizing constructions in Italian and other languages in which the distribution of strong and weak quantifiers as clefted constituents is similar to one in Cypriot Greek.

\footnotetext{
${ }^{17}$ This was pointed out by the anonymous reviewer who argues that these structures should be analysed as existential constructions.
} 


\section{Conclusion}

This paper examined the constraints on the distribution of quantifiers in clefts. It addressed the question as to why quantifiers are sometimes legitimate as clefted constituents and sometimes not. Using Cypriot Greek data, the paper showed that only quantifiers bearing a strong reading are allowed to occur in clefts (Agouraki 2010). The paper argued that this can be accounted for if we analyze Cypriot Greek clefts as expressing identificational focus (É. Kiss 1998). Strong quantifiers can express identificational focus as they satisfy the existence presupposition that is required for exhaustive identification to obtain. Quantifiers which bear a weak reading cannot satisfy this requirement. This can explain why the latter are banned in clefts, whereas the former are legitimate as clefted constituents. In light of the discussed data, the paper argued for a notion of exhaustive identification which allows for elements that do not denote individuals to occur in cleft pivots. Moreover, the paper adopted a view of exhaustive identification as 'exclusion by identification' (Kenesei 1986). However, what is considered to be excluded is not the complementary subset' as argued by É. Kiss (1998:261), but the contextually given set of alternatives. Under this analysis, the fact that universal quantifiers qualify for clefted constituents is accounted for. Finally, the paper argued that the analysis proposed for the Cypriot Greek clefts can carry over to crosslinguistic data accounting for similar constraints on the distribution of strong and weak quantifiers in focalizing constructions expressing identificational focus.

\section{Acknowledgements}

I am grateful to George Tsoulas for his insightful comments. I would also like to thank the anonymous reviewers for raising important points which improved my work. 


\section{References}

Agouraki, Y. (2010). It-clefts and stressed operators in the preverbal field of Cypriot Greek. Lingua 120, 527-554.

Barwise, J. \& Cooper, R. (1981). Generalized Quantifiers and Natural Language. Linguistics \& Philosophy 4, 159-219.

Benincà, P., Salvi, G. \& Frison, L. (1988). L'ordine degli elementi della frase e le costruzioni marcate. In Grande Grammatica italiana di consultazione, vol. I, eds. L. Renzi and G. Salvi, 115-225. Bologna: II Mulino.

Brunetti, L. (2004). A Unification of Focus. Unipress.

De Hoop, H. (1992). Case configuration and noun phrase interpretation. Ph.D.dissertation. Published in 1996. New York and London: Garland.

Dekany, E. (2010). The English cleft construction /t-clefts. The Odd Yearbook 8, 39-78.

Diesing, M. (1990). The Syntactic Roots of Semantic Partition. Ph.D. dissertation. University of Massachusetts.

Dufter, A. (2009). Clefting and discourse organization: Comparing Germanic and Romance. In Focus and background in Romance languages, eds. A. Dufter \& D. Jacob, 83-121. Amsterdam: John Benjamins.

Fotiou, C. (2009). Focusing strategies in Cypriot Greek. In Selected Papers from the 2006 Cyprus Syntaxfest, eds. K.K. Grohmann \& P. Panagiotidis, 63-91. Newcastle upon Tyne: Cambridge Scholars Publishing.

Gribanova, V. (2013). Copular clauses, clefts, and putative sluicing in Uzbek.

Language 89 (4), 830-882.

Halvorsen, P.-K. (1978). The syntax and semantics of cleft constructions. Austin, Texas: University of Texas.

Jackendoff, R. (1972). Semantic interpretation in generative grammar. Cambridge, MA: MIT press.

Kearns, K. (2000). Semantics. St. Martin's Press. 
Keenan, E. L. (1987). A Semantic Definition of "Indefinite NP". In The

Representation of (In)definiteness, eds. E. Reuland \& A. ter Meulen, 286-317. Cambridge, MA: MIT Press.

Kenesei, I. (1986). On the logic of Hungarian word order. In Topic, Focus and Configurationality, eds. W. Abraham \& S. de Meij, 143-159, Amsterdam: John Benjamins.

Kiss, É. K. (1998). Identificational Focus versus Information Focus. Language 74, 245-273.

McNally, L. (forthcoming). Strong and weak nominals. In Wiley's Companion to Semantics, eds. L. Matthewson, C. Meier, H. Rullmann \& T. E. Zimmermann. Retrieved from http://www.upf.edu/pdi/louisemcnally/_pdf/publications/strong_weak_McNally.pdf

Milsark, G. (1977). Peculiarities of the Existential Construction in English. Linguistic Analysis 3, 1-29.

Moltmann, F. (2005). Quantifier Domains and Presuppositions. Synthese 149, 179224.

Partee, B. (1988). Many Quantifiers. ESCOL 5, 383-402.

Percus, O. (1997). Prying open the cleft. NELS 27, 337-351.

Reeve, M. (2008). A pseudo-biclausal analysis of Slavonic clefts. UCL Working Papers in Linguistics 20, 63-85.

Reeve, M. (2012). Clefts and their relatives. Amsterdam: John Benjamins

Rooth, M. (1999). Association with focus or association with presupposition? In Focus: Linguistic, Cognitive, and Computational Perspectives, eds. P. Bosch \& R. van der Sandt, 232-244. Cambridge, UK: Cambridge University Press.

Szabolcsi, A. (1981). The semantics of topic-focus articulation. In Formal methods in the study of language, eds. J. Croenengijk, T. Janssen \& M. Stokhof, 513-41. Amsterdam: Matematisch Centrum.

Vallduví, E. \& Vilkuna, M. (1998). On Rheme and Kontrast. In The Limits of Syntax, eds. P. Culicover \& L. McNally, 79-106. New York: Academic Press. 
Zucchi, A. (1995). The Ingredients of Definiteness and the Definiteness Effect. Natural Language Semantics 3, 33-78. 